\title{
ACUTE APPENDIX-STATISTICS ON PATIENTS IN SOUTHEAST REGION OF THE REPUBLIC OF NORTHERN MACEDONIA IN THE PERIOD FROM 2015 TO 2020
}

\author{
Jihe Zhu ${ }^{1}$, Blagica Arsovska ${ }^{1,2}$, Kristina Kozovska ${ }^{1,3} 凹$ \\ Faculty of Medical Sciences, University Goce Delchev, Shtip, Republic of Macedonia. \\ ${ }^{2}$ Institute of Biology, Faculty of Natural Sciences and Mathematics, Skopje, Republic of Macedonia. \\ ${ }^{3}$ Medicine Faculty, St. Cyril and Methodius University of Skopje, Republic of Macedonia.
}

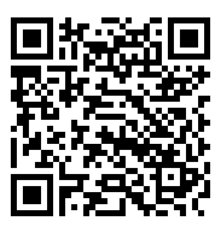

Received 18 September 2021

Accepted 18 October 2021

Published 31 October 2021

\section{CorrespondingAuthor}

Kristina Kozovska, tongdatangtcm@hotmail.com

DOI

10.29121/granthaalayah.v9.i10.2021 .4307

Funding: This research received no specific grant from any funding agency in the public, commercial, or not-for-profit sectors.

Copyright: (C) 2021 The Author(s). This is an open access article distributed under the terms of the Creative Commons Attribution License, which permits unrestricted use, distribution, and reproduction in any medium, provided the original author and source are credited.

\section{ABSTRACT}

In this research the analyzed data were obtained from the Department of Social Medicine of the Center for Public Health at PHI General Hospital - Strumica for patients with acute appendicitis from Strumica and from the department for Statistics of the Center for Public Health at PHI General Hospital - Gevgelija for patients with acute appendicitis from Gevgelija. 361 people diagnosed with acute appendicitis were analyzed in the period from 2015 to 2020 . According to the results most of the patients were hospitalized in $2015(20.2 \%)$ and $2016(20.2 \%)$. The majority of respondents are aged $0-24$ years $(67.5 \%)$, while males have a higher risk of developing this disease $(55,9 \%)$. in 2017 the number was 40 (14.9\%), in 2018, 43 (16\%), and in 2019 the number of hospitalized with acute appendicitis was $40(14.9 \%)$, equal to that in 2017 . The average age at hospitalization is 23.4 years, 22.8 years for men and 24 years for women. In the number of hospitalized people belonging to the first three age groups from 0 - 24 years, 25-44 years and $45-54$ years $(0-54)$, there is a higher prevalence of male (57.4\%) compared to female patients (42.6\%), while the number of hospitalized patients belonging to the age groups of 55-64, 65-74 and over 74 years there is a higher representation of female (58.3\%) compared to male patients $(41.7 \%)$. The average morbidity rate per 10,000 inhabitants in the Southeast region is 4.1, with an average rate of 3.5 in Gevgelija and an average rate of 4.8 in Strumica per 10,000 citizens. The incidence of acute appendicitis is highest in children, adolescents and young adults, and continuously decreases with age.

Keywords: Appendix, Appendicitis, Statistic, Acute

\section{INTRODUCTION}

Acute appendicitis is an acute inflammation of the appendix, typically due to obstruction of the lumen of the appendix. It is one of the most common causes of acute abdomen with necessary surgery in children and adults. It is estimated that about $8 \%$ of the general population will develop appendicitis, with the highest incidence in the second decade of life. Acute appendicitis is one of the most common causes of acute abdomen, especially in the young population. Patients affected by acute appendicitis usually complain of vaguely defined abdominal pain. It is continuously and rapidly deteriorating. Lack of appetite or anorexia is a feature of $80 \%$ of affected patients. Usually, in adults vomiting occurs in preexisting abdominal pain, while in children it may occur before its onset. Other non-specific symptoms that may be present are fever, diarrhea secondary to irritation of the inflamed appendix to the ileum, nausea, and constipation. 
Acute appendicitis is diagnosed based on the patient's physical examination, medical history and laboratory tests. Appendicitis scoring systems are needed to determine the guidelines in diagnosis. X-ray techniques are recommended if the diagnosis is not clinically confirmed.

Surgical removal of the appendix is considered the gold standard in the treatment of acute appendicitis. Recently, there is growing evidence that a nonsurgical approach to treatment is a viable alternative in certain clinical scenarios. Appendicitis is increasingly becoming a disease with many different perspectives that require different therapeutic strategies. Salminen et al. (2015), Feldman et al. (2016), Ferris et al. (2017), Bhangu et al. (2015), European Health Information Gateway, (2016), Tao et al. (2018)

\section{MATERIAL AND METHODS}

The data obtained from the Department of Social Medicine of the Center for Public Health at PHI General Hospital - Strumica for patients with acute appendicitis from Strumica and the surrounding settlements from the Southeast region, and from the Statistics Department of the Center for Public Health at the PHI General Hospital - Gevgelija for patients with acute appendicitis from Gevgelija and the surrounding settlements from southeast region for the period from 2015 to 2020 . The data obtained in this paper are systematized and presented in tables and graphs.

\section{RESULTS AND DISCUSSION}

Regarding the year of hospitalization of patients with acute appendicitis in the General Hospital - Strumica, the highest number was recorded in 2015, ie 55 $(20.5 \%)$ patients, and the lowest, ie $36(13.5 \%)$ patients were registered in 2020. In 2016 the number of patients was 54 (20.2\%), in 2017 the number was 40 (14.9\%), in 2018, $43(16 \%)$, and in 2019 the number of hospitalized with acute appendicitis was 40 (14.9\%), equal to that in 2017. There is a continuous decline in the number of hospitalized patients from 2015 to 2020 , while in 2020 there is a decline of $34.5 \%$ compared to 2015. Significant deviations in the number of hospitalizations are present in women, ie in 2020 the number of hospitalized patients is twice lower than the number of hospitalized in 2015, which is the basis for the continuous decline in the total number of hospitalized patients from 2015 to 2020.

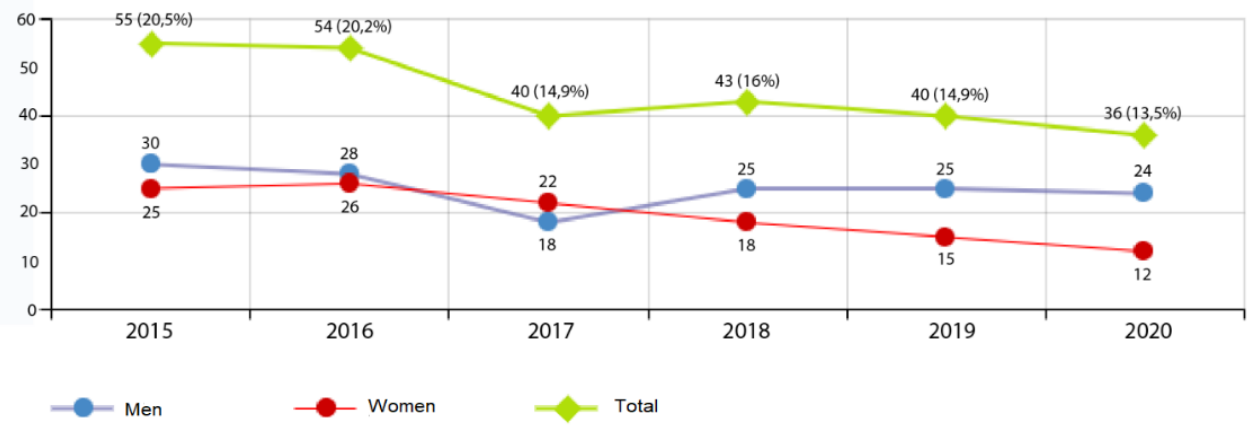

Chart 1 Acute appendicitis in Strumica and surrounding places sorted by year of diagnosing. 
in 2018. In 2015 and 2017 the number of patients was 18 (19.4\%), in 2019 the number of diagnosed was 13 (14\%) and in 2020 the number of patients was 15 (16.1\%). The largest decrease in the number of hospitalized patients is recorded between 2017 and 2018, ie in 2017 the number of hospitalized patients is approximately twice as high as the number of hospitalized in 2018. In 2019 and 2020 , there is a gradual increase compared to 2018.

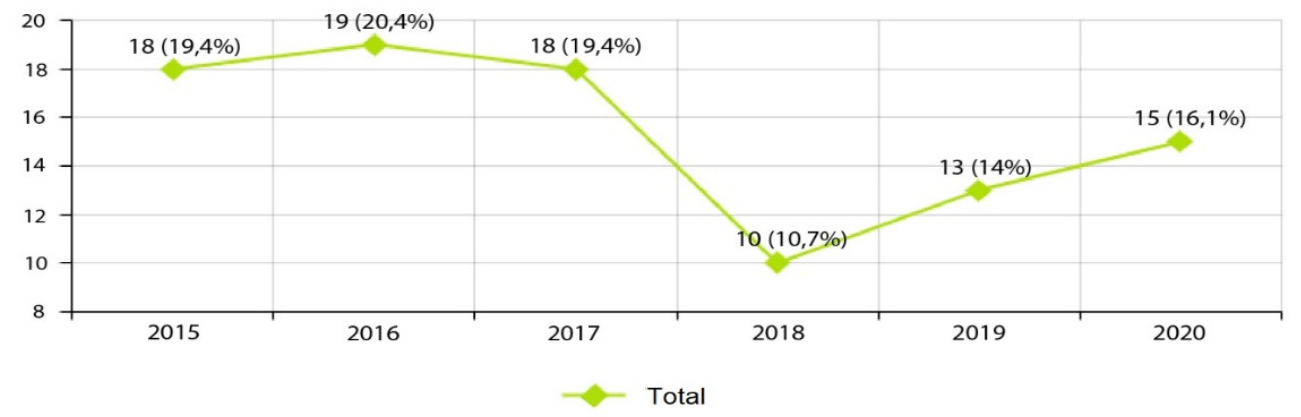

Chart 2 Acute appendicitis in Gevgelija and surrounding places. Distribution by year of diagnosis.

Out of a total of 268 people hospitalized and completely cared for in the General Hospital in Strumica, most of the patients, namely 181 are aged 0 - 24 years $(67.5 \%)$. Then follow 39 patients aged 25-44 years (14.5\%), 24 patients aged 45-54 (9\%), 14 patients aged $55-64(5.2 \%), 9$ patients aged $65-74$ years $(3.4 \%)$ and only one case $(0.4 \%)$ recorded at the age of over 74 years. In the number of hospitalized people belonging to the first three age groups from 0 - 24 years, 25-44 years. and 45-54. (054 years) there is a higher prevalence of males (57.4\%) compared to females (42.6\%), in a ratio of 1.4: 1 in favor of males, while the number of hospitalized patients belonging to the age groups of 55-64, 65-74. and over 74 years there is a higher representation of females (58.3\%) compared to males $(41.7 \%)$, in a ratio of 1.4: 1 in favor of females.

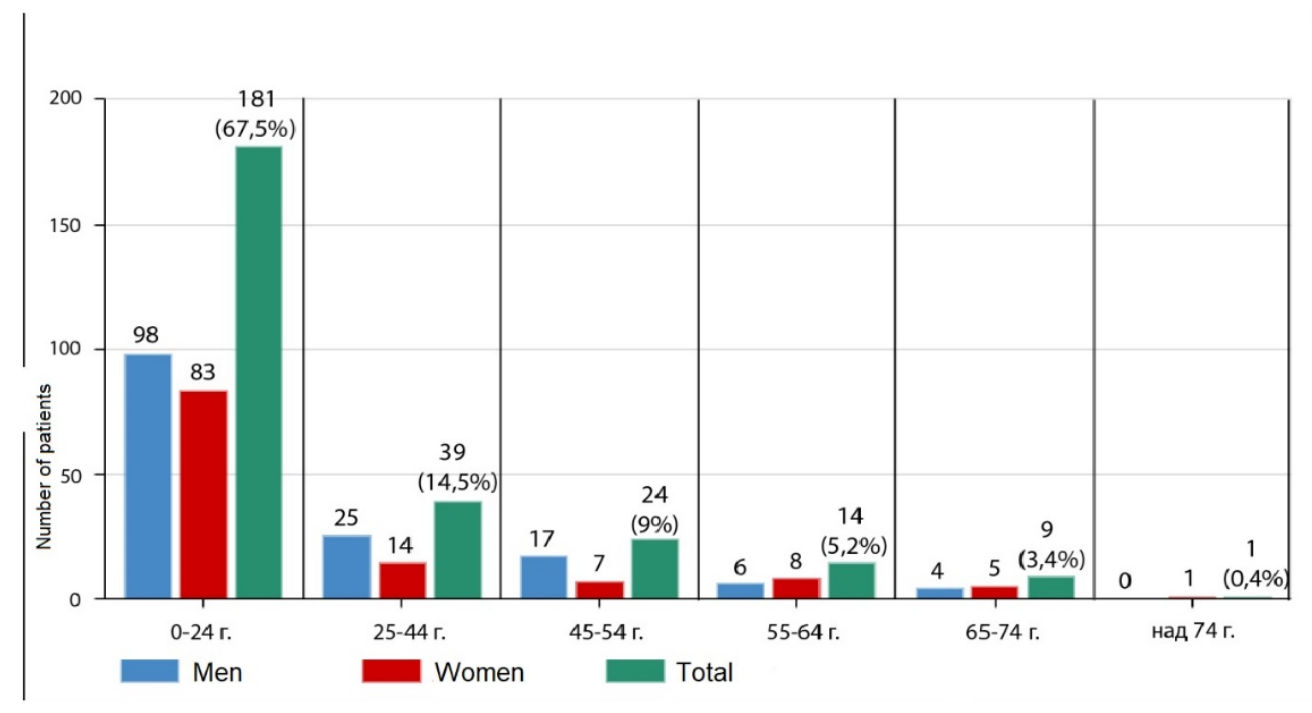

Chart 3 Acute appendicitis in the period from 2015 - 2020 in Strumica and surrounding places. Distribution by gender and age groups

The average age of hospitalized patients in the period from 2015 to 2020 in Strumica is 23.4 years. The average age for males is 22.8 years, and for females it is 
24 years. For males, the lowest average age of hospitalization is 15 years recorded in 2017, and the highest is 34 years in 2020, which is more than twice the average age compared to that in 2017. For women, the lowest average age of hospitalization is 18 years set in 2016, and the highest is 32 years in 2020. Only in 2017 and 2018 there is a higher average age of hospitalization in females (27 years and 23 years) compared to males (15 years and 19 years), while in 2015, 2016, 2019 and 2020 a slightly higher average age of hospitalization is observed in males.

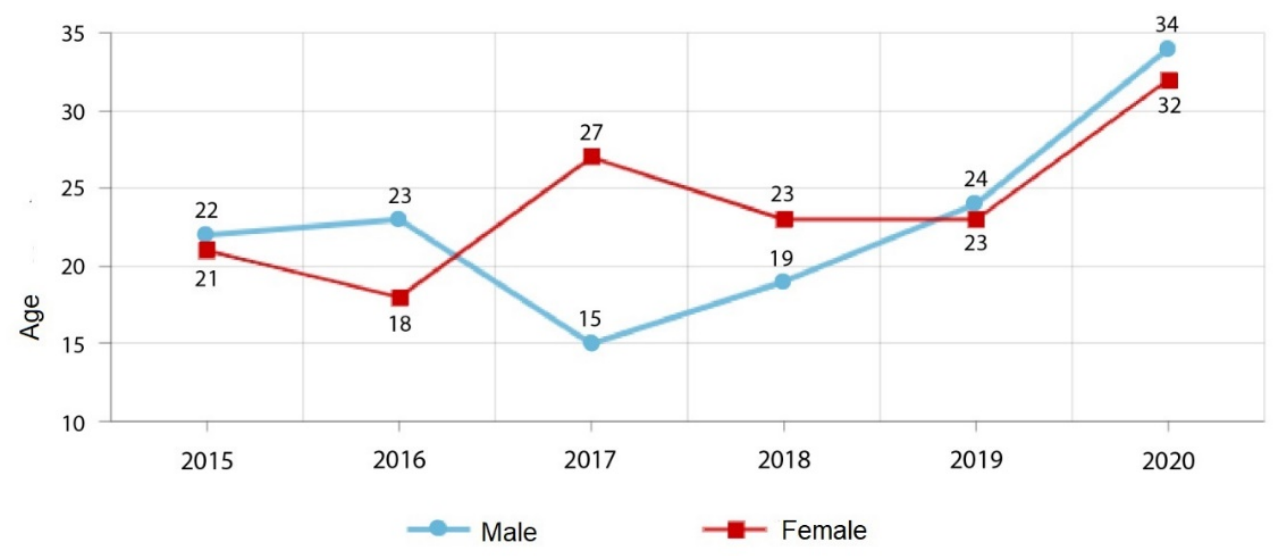

Chart 4 Acute appendicitis in the period from 2015 - 2020 in Strumica and surrounding places. Distribution by gender and average age at hospitalization

Regarding the gender of the hospitalized patients in the period from 2015 to 2020 in the General Hospital - Strumica, 150 (55.97\%) patients belong to the male, while 118 (44.03\%) patients are female.

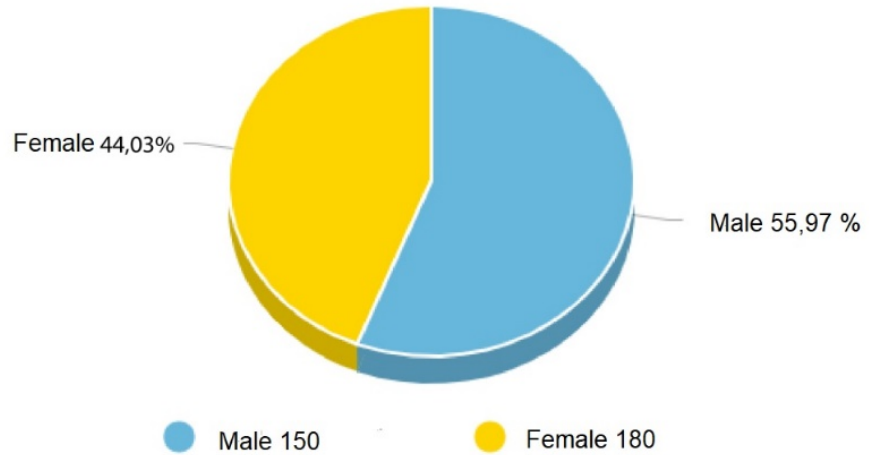

Chart 5 Acute appendicitis in the period from 2015 - 2020 in Strumica and surrounding places. Distribution by gender at hospitalization

Regarding the morbidity expressed per 10,000 inhabitants of the hospitalized patients with acute appendicitis in the General Hospital - Strumica, the highest morbidity rate of 5.9 was recorded in 2015, and the lowest, or 3.9 was recorded in 2020. In 2016 the rate is 5.8, in 2017 and 2019 it is 4.3, and in 2018 the morbidity rate of hospitalized patients with acute appendicitis per 10,000 inhabitants is 4.6. Regarding the morbidity expressed per 10,000 inhabitants of hospitalized patients with acute appendicitis in the General Hospital - Gevgelija, the highest morbidity rate of 4.3 was recorded in 2016, and the lowest, or 2.3 was recorded in 2018, approximately twice less than the previous 2017. In 2015 and 2017 the rate is 4.1, 
in 2019 the rate is 2.9 , and in 2020 the morbidity rate of hospitalized patients with acute appendicitis per 10,000 inhabitants is 3.4.

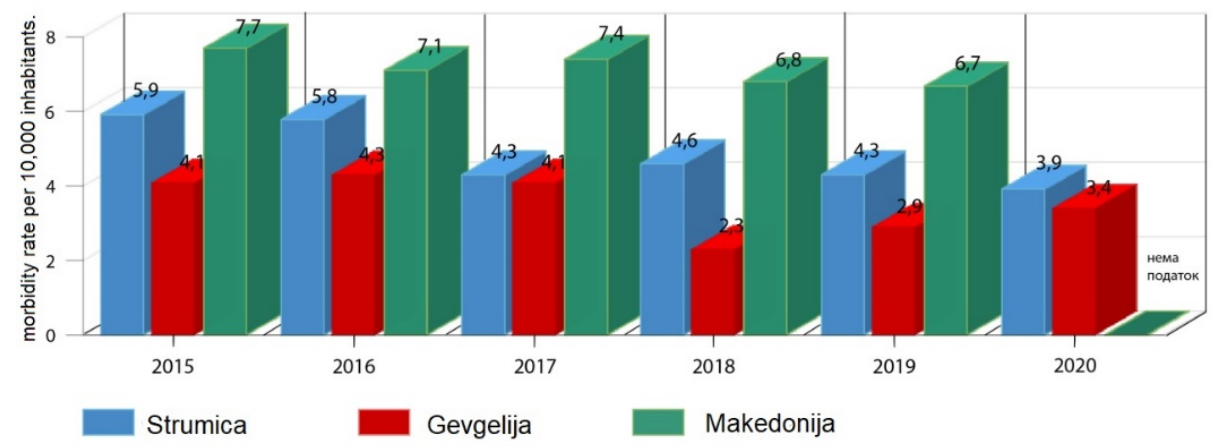

Chart 6 Acute appendicitis in the period from 2015 - 2020 in Strumica, Gevgelija and Macedonia. Distribution by morbidity rate per 10,000 inhabitants

For comparison, in N. Macedonia average rate was 7.1 in the analyzed period, excluding 2020. In fact, there is a continuously higher morbidity rate in $\mathrm{N}$. Macedonia in relation to Strumica and / or Gevgelija in the period covered in this analysis.

\section{CONCLUSION}

Acute appendicitis is one of the most common digestive diseases affecting the young population in the Southeast region of the Republic of N. Macedonia in the period 2015 - 2020. One of the main goals in the future would be to improve the diagnosis of appendicitis, especially the diagnostic ability to distinguish different forms of appendicitis. In addition, further scientific research into the appendix microbiome and its role in pathogenesis would contribute to a better understanding of the disease.

\section{REFERENCES}

Bhangu A, Søreide K, Di Saverio S, et al. (2015) Acute appendicitis: modern understanding of pathogenesis, diagnosis, and management. Lancet;386:1278-87. Retrieved from https://doi.org/10.1016/S01406736(15)00275-5

\section{European Health Information Gateway,}

$(2016$

). Retrieved from https://gateway.euro.who.int/en/indicators/hfa_5506450-sdr-appendicitis-all-ages-per-100-000

Feldman M, Friedman LS, Brandt LJ. (2016) Sleisenger and Fordtran's Gastrointestinal and Liver Disease: Pathophysiology, Diagnosis, Management. Elsevier Saunders;.

Ferris M, Quan S, Kaplan BS, Molodecky N, Ball CG, Chernoff GW, Bhala N, Ghosh S, Dixon E, Ng S, Kaplan GG. (2017) The Global Incidence of Appendicitis: A Systematic Review of Population-based Studies. Ann Surg. Aug;266(2):237241. Retrieved from https://doi.org/10.1097/SLA.0000000000002188

Salminen P, Paajanen H, Rautio T, et al. (2015) Antibiotic Therapy vs Appendectomy for Treatment of Uncomplicated Acute Appendicitis: The APPAC 
Jihe Zhu, Blagica Arsovska, and Kristina Kozovska

$\begin{array}{lrllll}\text { Randomized Clinical Trial.. } & \text { JAMA } & ; \text { 313(23): } & \text { p.2340-8. } & \text { doi: } \\ \text { 10.1001/jama.2015.6154. } & & \text { Retrieved } & & \text { from }\end{array}$
https://doi.org/10.1001/jama.2015.6154

Tao Le, Vikas Bhushan, Deol M, Reyes G. (2018) First Aid for the USMLE Step 2 CK, Tenth Edition. McGraw-Hill Education. 